\title{
Diagnosing Inherited Platelet Disorders: Modalities and Consequences
}

\author{
Carlo Zaninetti ${ }^{1,2}$ Martina Wolff ${ }^{1} \quad$ Andreas Greinacher ${ }^{1}$ \\ ${ }^{1}$ Institut für Immunologie und Transfusionsmedizin, \\ Universitätsmedizin Greifswald, Greifswald, Germany \\ 2 Department of Internal Medicine, University of Pavia, Pavia, Italy \\ Address for correspondence Prof. Dr. Andreas Greinacher, Institut für \\ Immunologie und Transfusionsmedizin, Abteilung \\ Transfusionsmedizin, Sauerbruchstr. 17487 Greifswald, Germany \\ (e-mail: andreas.greinacher@med.uni-greifswald.de).
}

Hamostaseologie 2021;41:475-488.

\author{
Abstract \\ Keywords \\ - inherited platelet \\ disorders \\ - hereditary \\ thrombocytopenias \\ - bleeding tendency \\ - blood smear \\ - genetic testing
}

Inherited platelet disorders (IPDs) are a group of rare conditions featured by reduced circulating platelets and/or impaired platelet function causing variable bleeding tendency. Additional hematological or non hematological features, which can be congenital or acquired, distinctively mark the clinical picture of a subgroup of patients. Recognizing an IPD is challenging, and diagnostic delay or mistakes are frequent. Despite the increasing availability of next-generation sequencing, a careful phenotyping of suspected patients-concerning the general clinical features, platelet morphology, and function-is still demanded. The cornerstones of IPD diagnosis are clinical evaluation, laboratory characterization, and genetic testing. Achieving a diagnosis of IPD is desirable for several reasons, including the possibility of tailored therapeutic strategies and individual follow-up programs. However, detailed investigations can also open complex scenarios raising ethical issues in case of IPDs predisposing to hematological malignancies. This review offers an overview of IPD diagnostic workup, from the interview with the proband to the molecular confirmation of the suspected disorder. The main implications of an IPD diagnosis are also discussed.

\section{Introduction}

Inherited platelet disorders (IPDs) are a group of rare conditions featured by reduced platelet count and/or impaired platelet function. ${ }^{1,2}$ In early 2021, IPDs comprise more than 30 well-defined entities and more than 50 responsible genes. ${ }^{3}$ Their prevalence is currently estimated between 2 and 3:100,000 individuals, but it is probably underestimated. Our laboratory receives per week blood samples of approximately 10 to 15 new patients in whom hereditary platelet disorders are suspected. Around 15,000 patients per year undergo diagnostic investigation for IPD worldwide, and in about one-third the suspicion is eventually confirmed. ${ }^{4,5}$ IPD pathogenesis and clinical presentation are heterogeneous. ${ }^{6}$ In particular, the bleeding symptoms range from trivial to severe, and the therapeutic needs of patients are quite diverse. ${ }^{7,8}$ Often, platelet

received

January 8, 2021

accepted after revision

May 19, 2021 changes are associated with syndromic pictures due to congenital or acquired manifestations even beyond hemostasis. $^{9}$

Advances in the knowledge of IPDs acquired over the past 15 years have opened new diagnostic and management strategies. ${ }^{10}$ However, recognizing an IPD is challenging, and diagnostic delay or mistakes are frequent. In fact, IPD diagnosis is often made in patients of mature age. Especially if the IPD results in thrombocytopenia, up to $30 \%$ of the affected patients are initially erroneously diagnosed as having immune thrombocytopenia (ITP), sometimes receiving ineffective immunosuppressive medications and even splenectomy. ${ }^{11,12}$ Despite the growing availability of next-generation sequencing in the diagnostic field, a careful phenotyping of patients is still demanded. ${ }^{13}$

The main ways of IPD diagnosis are clinical evaluation-to raise the correct suspicion-laboratory characterization with

$\begin{array}{ll}\text { @ 2021. Thieme. All rights reserved. } & \text { DOI https://doi.org/ } \\ \text { Georg Thieme Verlag KG, } & \text { 10.1055/a-1515-0813. } \\ \text { Rüdigerstraße 14, } & \text { ISSN 0720-9355. } \\ 70469 \text { Stuttgart, Germany } & \end{array}$


Table 1 Advantages and disadvantages of IPD diagnostic approaches

\begin{tabular}{|c|c|c|}
\hline Approach & Advantages & Disadvantages \\
\hline Clinical evaluation & $\begin{array}{l}\text { - Some acquired conditions can be excluded } \\
\text { - The hereditary nature and the inheritance pattern of the } \\
\text { disease can emerge } \\
\text { - Possibility to detect congenital defects/syndromic } \\
\text { pictures } \\
\text { - Allows standardized collection of bleeding history }\end{array}$ & $\begin{array}{l}\text { - Time consuming } \\
\text { - Silent family histories do not } \\
\text { exclude IPDs } \\
\text { - Bleeding phenotype can be blurred } \\
\text { or absent }\end{array}$ \\
\hline $\begin{array}{l}\text { Blood smear assessment- } \\
\text { light microscopy }\end{array}$ & $\begin{array}{l}\text { - Reliable estimation of platelet number and size } \\
\text { - Evaluation of platelet granularity } \\
\text { - Small amount of blood is needed } \\
\text { - Relatively cheap and rapid }\end{array}$ & $\begin{array}{l}\text { - Operator-dependent readout } \\
\text { - Preanalytical artifacts can occur }\end{array}$ \\
\hline $\begin{array}{l}\text { Blood smear assessment- } \\
\text { immunofluorescence } \\
\text { microscopy }\end{array}$ & $\begin{array}{l}\text { - Capacity to confirm (e.g., MYH9-RD) or highly suggest } \\
\text { specific IPDs (e.g., BSS, GT, TUBB1-RT, GFI1B-RT, FLNA-RT) } \\
\text { - Small amount of blood is needed } \\
\text { - Relatively cheap and rapid } \\
\text { - Samples can be shipped safely even long distances }\end{array}$ & $\begin{array}{l}\text { - Technically demanding } \\
\text { - Semiquantitative method } \\
\text { - Operator-dependent readout }\end{array}$ \\
\hline Platelet function assays & $\begin{array}{l}\text { - Assessment of the same platelet function pathway from } \\
\text { different points of view } \\
\text { - Gold standard for some IPDs (e.g., BSS, GT) } \\
\text { - Quantitative confirmation of some alterations }\end{array}$ & $\begin{array}{l}\text { - Low level of standardization } \\
\text { - Poorly automatized } \\
\text { - Relatively large amount of blood is } \\
\text { needed } \\
\text { - Tight timing for processing } \\
\text { samples } \\
\text { - Low sensitivity for mild defects of } \\
\text { platelet function }\end{array}$ \\
\hline Genetic testing & $\begin{array}{l}\text { - Diagnostic certainty } \\
\text { - Targeted gene panels for subgroups of IPDs } \\
\text { - Relatively cheap and rapid } \\
\text { - Novel genes responsible for IPDs can be identified (WES, } \\
\text { WGS) }\end{array}$ & $\begin{array}{l}\text { - Poor diagnostic rate in patients } \\
\text { with blurred phenotype } \\
\text { - Need of skilled expertise for VUS } \\
\text { interpretation } \\
\text { - Investigations on new genes } \\
\text { require further studies } \\
\text { - Incidental findings can raise ethical } \\
\text { concerns }\end{array}$ \\
\hline
\end{tabular}

Abbreviations: BSS, Bernard-Soulier syndrome; GT, Glanzmann thrombasthenia; IPDs, inherited platelet disorders; VUS, variants of uncertain significant; WES, whole-exome sequencing; WGS, whole-genome sequencing.

traditional and novel approaches, and molecular investigations ( - Table 1 ).

A confirmed diagnosis is relevant for many reasons including tailored therapeutic choices and individual followup programs. However, it can also open complex scenarios with delicate ethical concerns.

The aim of this review is to offer an overview of IPD diagnostic workup, in an integrated fashion, from the interview with the suspected patient to genetic confirmation. The main implications of a diagnosis of an IPD are also addressed.

\section{Modalities of Inherited Platelet Disorders Diagnosis}

\section{Clinical Evaluation}

The collection of personal and family history, together with the physical examination, represents the cornerstone of clinical evaluation of suspected patients. Patient's history can reveal thrombocytopenia or bleeding symptoms in the relatives, and even suggest the hereditary pattern of the disease (e.g., autosomal dominant or X-linked if the picture presents in all generations regardless of the sex or only in male subjects, respectively). Information on additional congenital or acquired manifestations shared within the pedigree should be carefully searched. For instance, a juvenile hearing defect frequently hits patients with MYH9-related disease (MYH9-RD) or DIAPH1-related thrombocytopenia (DIAPH1-RT), ${ }^{14,15}$ and eczema and immunodeficiency are associated with Wiskott-Aldrich syndrome/X-linked thrombocytopenia (WAS/XLT). ${ }^{16,17}$ Sometimes, such non hematological features affect the quality of life of the patients more than the platelet disorder itself. However, a silent family history does not exclude a genetic defect of platelets, as de novo mutations can be relatively frequent in some IPDs, such as in MYH9-RD. ${ }^{18}$ Therefore, a platelet defect of genetic origin should be suspected whenever a hint of an acquired condition (e.g., occurrence of thrombocytopenia and/or bleeding symptoms with former normal platelet counts and/or in the absence of previous hemorrhagic diathesis) cannot be found, independently of the age of the proband.

When assessing the bleeding history, the entire lifetime should be taken into account, and both spontaneous and provoked symptoms should be collected. IPD bleeding diathesis is typically mucocutaneous, with epistaxis, 
menorrhagia, cutaneous-, and oral cavity bleeds as the most frequently reported symptoms. ${ }^{19}$ The number and the intensity of bleedings is substantially higher in IPDs with defective platelet function than in IPDs with thrombocytopenia only. In fact, patients affected with the most severe dysfunctional forms such as Glanzmann thrombasthenia (GT) and biallelic Bernard-Soulier syndrome (BSS)-or with platelet counts lower than $50 \times 10^{9} / \mathrm{L}$-usually show the most serious hemorrhagic manifestations. ${ }^{20}$ On the other hand, the majority of IPD patients with mild or moderate thrombocytopenia and preserved platelet function have trivial or no bleedings at all. ${ }^{19}$ In any case, upon traumas, invasive procedures, or use of drugs impairing platelet function, hemorrhagic symptoms can emerge even in these patients. Therefore, the patients are to be asked also about bleedings occurring in conjunction with use of anti-inflammatory compounds or viral infections. The latter can lead to a transient reduction of platelet count. ${ }^{21}$

The use of validated bleeding assessment tools (BATs) such as the World Health Organization (WHO) scale and the International Society of Thrombosis and Haemostasis (ISTH)BAT is highly recommended. ${ }^{22-25}$ The WHO scale is a global, nonstructured tool that categorizes bleeding into four groups: grade 0 , no bleeding; grade 1 , cutaneous bleeding only; grade 2, mild blood loss; grade 3 , gross blood loss; and grade 4 , debilitating blood loss. Conversely, the ISTH-BAT sums 14 distinct scores corresponding to specific graduated bleeding manifestations. In a recent study involving a large series of patients with different IPDs, the ISTH-BAT showed a higher discriminative power with respect to WHO scale in distinguishing IPD patients from healthy controls and patients with bleeding manifestations due to von Willebrand disease (vWD). ${ }^{19}$ Notably, patients with a cumulative score higher than 6-for whom vWD had been excluded-had a very high probability of being affected by an IPD. A subsequent follow-up study showed that the ISTH-BAT is a useful tool also for the prediction of future bleedings in IPD patients, and may help identify cases requiring more aggressive treatment. ${ }^{26}$

A meticulous physical examination can also identify peculiar defects associated with a group of syndromic IPDs such as skeletal deformations, facial dimorphisms, or myopathy. ${ }^{27-33}$ These clinical aspects have been recently addressed in two review articles authored by Nurden and colleagues. ${ }^{1,2}$

\section{Immunomorphologic Analysis of Blood Smear}

For a long time, the role of the blood smear remained confined to the identification of few, relevant parameters assessable on May-Grünwald-Giemsa-stained slides by light microscopy. ${ }^{7}$ These elements are the visual estimation of the real platelet count (which can be underestimated by automated cell counters in patients with platelet macrocytosis), ${ }^{34}$ the platelet dimension, and the platelet granularity (-Fig. 1). The mean platelet diameter (MPD) represents a major classification criterion for IPDs. ${ }^{7}$ By evaluating a cohort of patients affected with 19 disorders, Noris and collaborators distinguished forms with enlarged (i.e., $>3.2 \mu \mathrm{m}$ ), decreased (i.e., $<2.6 \mu \mathrm{m}$ ), and normal (i.e., 2.6-3.2 $\mu \mathrm{m}$ ) MPD. ${ }^{35}$ In particular, an MPD larger than $3.9 \mu \mathrm{m}$ or smaller than $2.6 \mu \mathrm{m}$ showed high sensitivity and specificity in discerning IPDs featured by giant platelets (i.e., BSS and MYH9-RD) from forms with small platelets (i.e., WAS/XLT and TAR). ${ }^{35}$

A profound reduction of platelet staining is typically found in gray platelet syndrome (GPS), where $\alpha$-granules

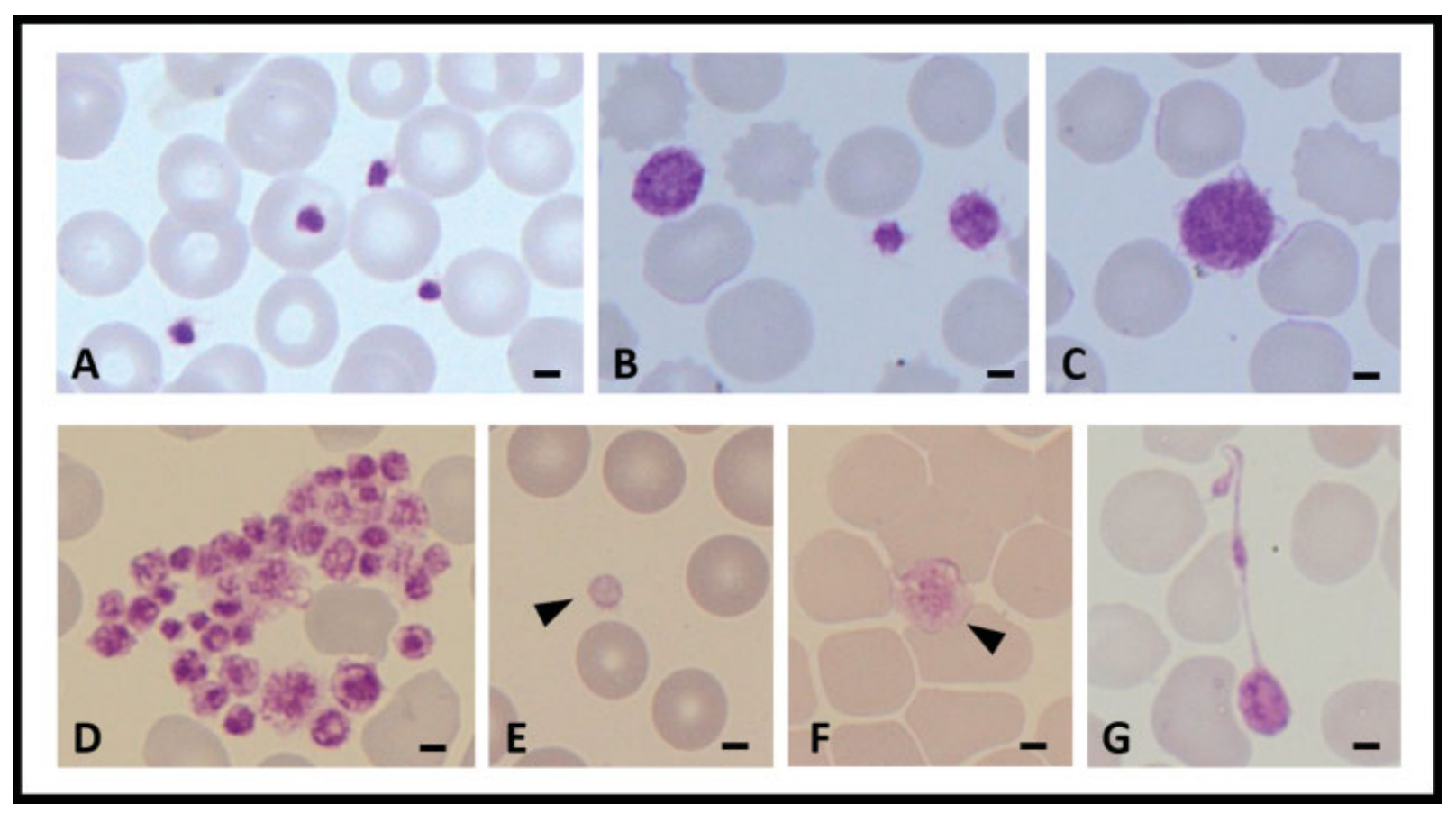

Fig. 1 Morphologic abnormalities of platelets by light microscopy. Alterations of platelet dimension. (A) With respect to control, (B) platelets may appear enlarged, (C) or giant. Changes of platelet distribution, staining, and shape. (D) A platelet aggregate, (E) a "pale" platelet due to reduced granularity, (F) a vacuolated platelet, and (G) an abnormally elongated platelet, somewhat resembling a proplatelet, in a patient affected with thrombocytopenia due to IKZF5 mutations. ${ }^{52}$ Scale bars correspond to $2 \mu \mathrm{m}$. 


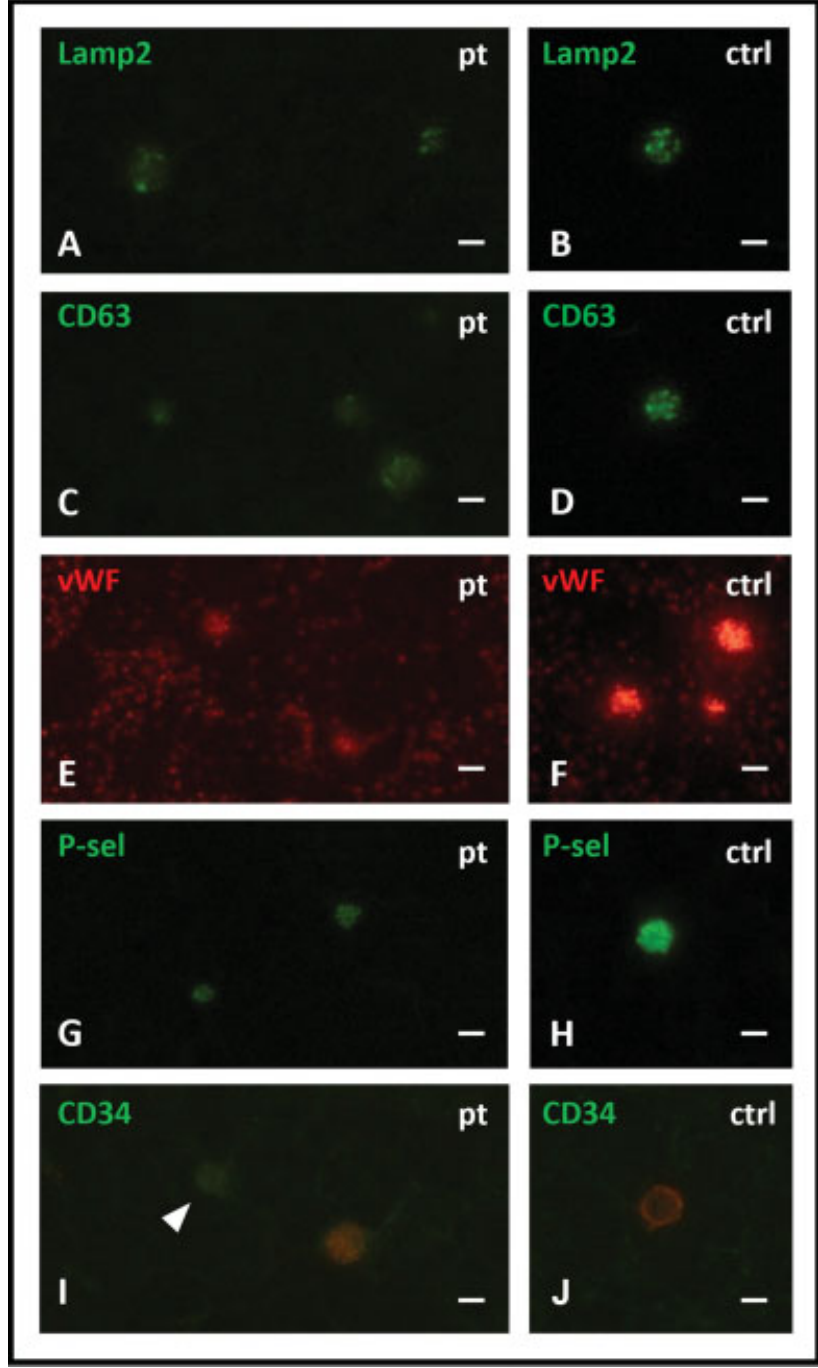

Fig. 2 Immunofluorescence findings in a patient with Jacobsen syndrome. The markers of dense granules (A) Lamp 2 and (C) CD63 are reduced and sometimes diffused throughout the cell with respect to controls (B and D, respectively). The markers of $\alpha$-granules (E) von Willebrand factor and $(G)$ P-selectin appear reduced in comparison with controls ( $\mathrm{F}$ and $\mathrm{H}$, respectively). (I) In nearly half of the platelets, the expression of the stem cell antigen CD34 was detectable with respect to control $(\mathrm{J})$. Scale bars correspond to $2 \mu \mathrm{m}$. ctrl = healthy control, pt = patient.

are almost absent. ${ }^{36}$ In other IPDs such as GFI1B-related thrombocytopenia (GFI1B-RT) or GATA1-related thrombocytopenia (GATA1-RT), the reduction of azurophilic granules is suggestive, albeit partial. ${ }^{37,38}$ Alpha granules can also appear enlarged or disturbed in thrombocytopenia Paris-Trousseau (TCPT)/Jacobsen syndrome ${ }^{29}$ ( - Fig. 2), and large vacuoles can be detected in platelets of GATA1-RT patients. ${ }^{38}$

The presence of platelet clumps ( - Fig. 1D) can suggest type 2B- or platelet-type vWD. ${ }^{39-41}$

In addition, some morphologic changes of other peripheral blood cells can be of great aid. For instance, "Döhle-like" bodies in granulocytes are pathognomonic for MYH9-RD, ${ }^{42}$ and alterations of the shape or dimension of the red blood cells can suggest GATA1-RT (prominent difference in size and dimension of erythrocytes, i.e., anisopoikilocytosis) or
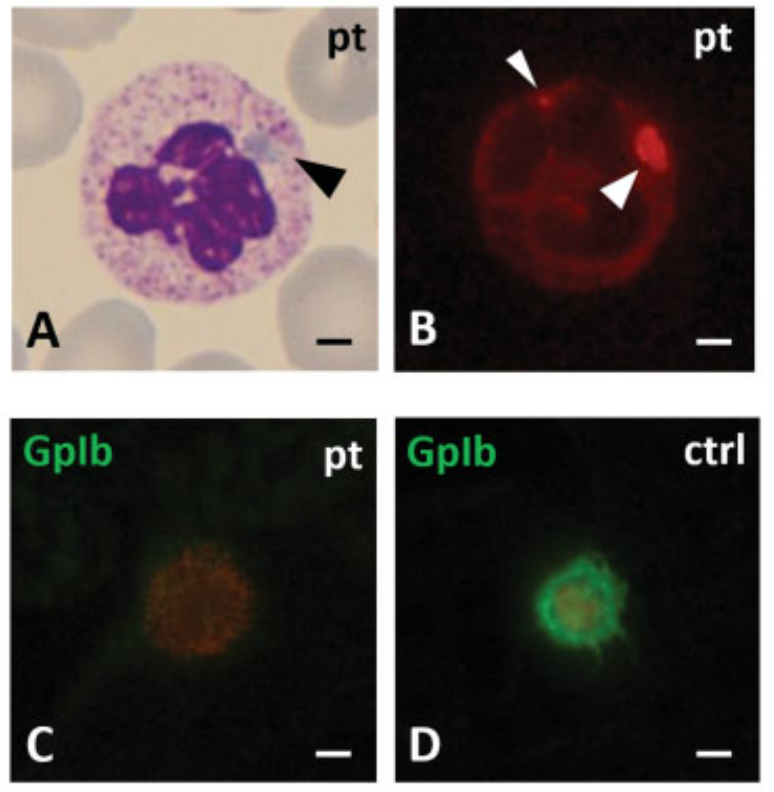

Fig. 3 Diagnostic pattern of biallelic Bernard-Soulier syndrome and MYH9-related disease. MYH9-related disease. The pathognomonic inclusions of non-muscle myosin IIA in the leukocytes are evident either (A) by light- or (B) immunofluorescence microscopy. BernardSoulier syndrome. (D) In comparison with the control, (C) patients' platelets show the absence of Gplb. Scale bars correspond to $2 \mu \mathrm{m}$. $\mathrm{ctrl}=$ healthy control, $\mathrm{pt}=$ patient.

thrombocytopenia associated with sitosterolemia (red cell resembling a mouth, i.e., stomatocytosis). ${ }^{43,44}$

Recently, a novel investigational approach on the blood smear has been proposed as a diagnostic tool for IPDs. ${ }^{45}$ The method is based on the assessment of a series of platelet proteins stained with monoclonal antibodies by immunofluorescence microscopy. These are membrane receptors (i.e., GpIbIX and GpIIb/IIIa), $\alpha$ - (i.e., von Willebrand factor, Pselectin, thrombospondin) or dense granule, and lysosome membrane components (i.e., Lamp 1, Lamp 2, and CD63), cytoskeletal markers (e.g., non-muscular myosin IIA, $\alpha$ - and B1-tubulin, filamin A), or the stem-cell antigen CD34. ${ }^{46}$ This technique has preliminary proved to be effective in recognizing a group of IPDs, which had been previously confirmed by genetic testing or standard laboratory tools. ${ }^{45}$

In combination with light microscopy, immunofluorescence assessment of the blood smear can provide diagnosis by itself, as in the case of MYH9-RD ( - Fig. 3A, B) or in addition to established platelet function assays (see below). This is the case of GT and BSS ( - Fig. 3C, D) including the monoallelic variants of these disorders, which are also featured by dominant macrothrombocytopenia (i.e., ITGA2B/ITGB3-related thrombocytopenia and monoallelic BSS). ${ }^{47,48}$ Alterations of granule content representing the principal sign or a component of some IPDs can be distinctly visualized ( - Fig. 1E, F). ${ }^{45}$ By labelling cytoskeletal proteins, diagnostic patterns have been proposed for TUBB1-related thrombocytopenia (TUBB1-RT), FLNA-related thrombocytopenia (FLNA-RT), and WAS. ${ }^{45,49,50}$ A positive staining for CD34, which is normally absent on mature platelets, hints 
to GFI1B-RT. ${ }^{51}$ We have also observed expression of CD34 in a subpopulation of platelets in a patient with Jacobsen's syndrome (-Fig. 2I).

A major advantage of the method is the need of small amounts of blood $(<100 \mu \mathrm{L})$, thus making the analysis achievable even in newborns, and the possibility to ship samples to be assessed even long distances. Although it requires specialized expertise, it is relatively cheap and not excessively time-consuming. Even beyond the diagnostic spectrum of IPDs, this approach can provide clinicians with relevant information about the bleeding (or prothrombotic) phenotype of patients. For instance, the presence of a disturbance of granules can suggest the patient may have an increased risk of provoked bleeding. On the other hand, the presence of platelet clumps associated with mild alterations of granule- and cytoskeleton markers can suggest in vivo platelet preactivation, which can act as additional risk for thrombotic complications in case of systemic inflammatory responses, or may explain increased risk of bleeding because platelets are exhausted. In this case, platelet transfusion is likely more effective than desmopressin. In addition, features of platelets can be identified, which had been either not described before, like strongly enhanced formation of tethers containing GpIIb/IIIa ( - Fig. 4C), or which seem to be typical for certain genetic changes, like irregularly shaped platelets in thrombocytopenia due to mutations of $I K Z F 5^{52}$ (- Fig. 1G). A strength of immunofluorescence seems to be the identification of patients with dominant forms of GT. They show a typical pattern characterized by prevalent intracellular staining of GpIIb/IIla in platelets (-Fig. 4A).

However, one has to keep in mind that artifactual alterations of cytoskeletal- and granule markers can also occur because of preanalytical issues such as cold storage of the blood tube before preparing the smear. Moreover, platelets can be altered by EDTA or by mechanical stress in case of smears obtained by finger prick. ${ }^{53}$ However, none of the currently available morphological markers of platelet activation can differentiate between artifactual and spontaneous (e.g., due to signaling defect such as in dominant GT) causes of platelet preactivation.

\section{Platelet Function Tests}

\section{Platelet Aggregation}

Light-transmission aggregometry (LTA), which was set for the first time more than 50 years ago, still represents the gold standard for the evaluation of in vitro platelet aggregation. ${ }^{54}$ Platelets suspended in a platelet-rich plasma (PRP)-stirred sample are stimulated with defined concentration of diverse agonists (e.g., ristocetin, collagen, adenosine diphosphate [ADP], arachidonic acid, and epinephrine). The entity of platelet aggregation over time is measured by the evaluation of the capacity of a light beam to pass through the sample, which is proportional to the clarity of the suspension due to the formation of platelet aggregates. ${ }^{55}$

Some LTA patterns are highly suggestive for specific IPDs. ${ }^{56}$ For instance, the absence of platelet aggregation with all agonists with the exception of (high-concentrations of) ristocetin or isolated impaired aggregation in response to (high-concentrations of) ristocetin is diagnostic for classical GT and biallelic BSS, respectively. ${ }^{6,57,58}$ In other cases, peculiar patterns can greatly narrow down the diagnostic spectrum, although further studies are required for confirmation, for example, in case of increased response to low concentrations of ristocetin, hinting to platelet type (PT)- or type $2 \mathrm{~B}$ vWD, which can then be distinguished using ristocetininduced platelet aggregation after mixing normal platelets with patient's plasma and patient's platelets with normal plasma. ${ }^{39,40,59,60}$ On the other hand, isolated impaired collagen-induced aggregation can suggest GpVI deficiency. ${ }^{61}$

The use of additional agonists can differentiate IPDs leading to apparently similar aggregation patterns, as for

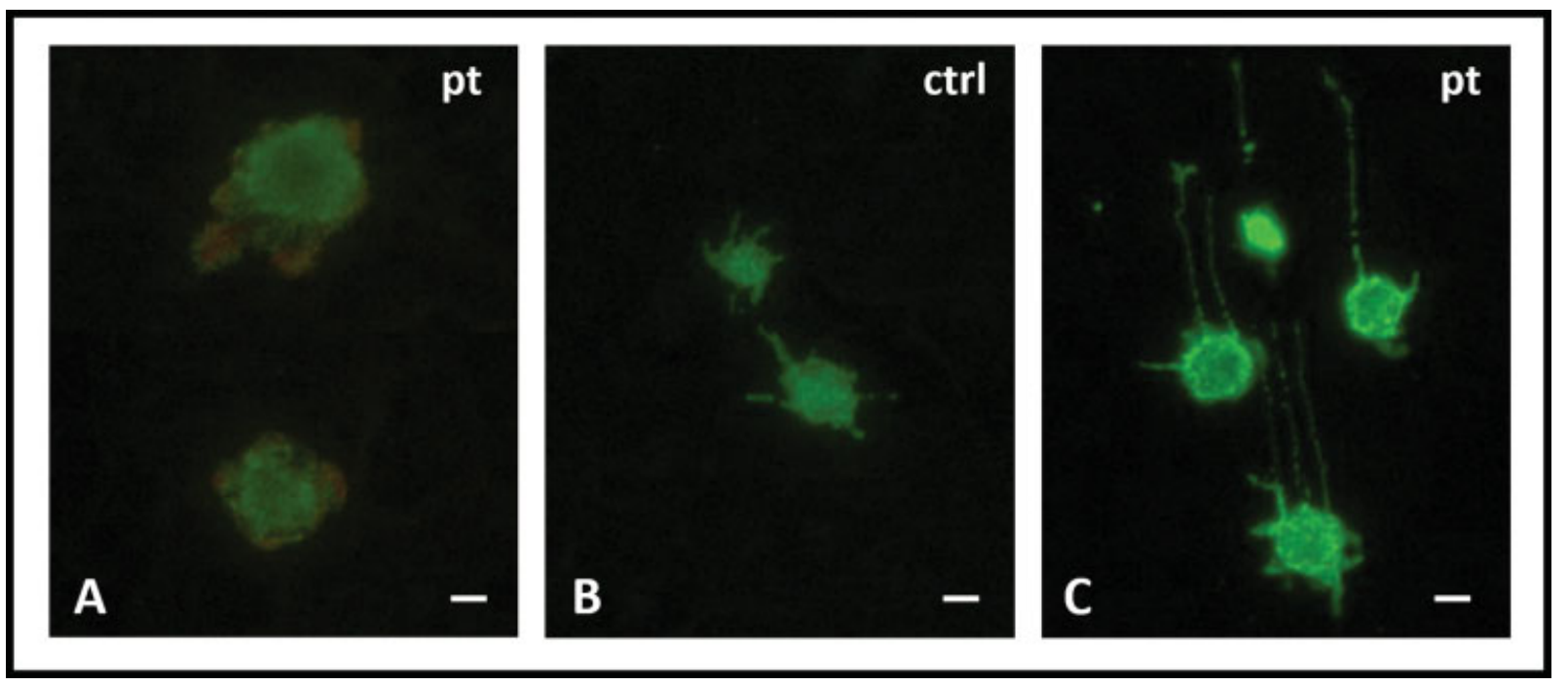

Fig. 4 Peculiar alterations of Gpllb/IIla distribution by immunofluorescence microscopy. (B) With respect to control, (A) in a patient with dominant Glanzmann thrombasthenia Gpllb/IIla appears mainly intracellularly distributed and not expressed in the pseudopodia. (C) In a patient with in vivo platelet preactivation, peculiar elongations of platelet membrane ("tethers") containing GplIb/IIla are evident. Scale bars correspond to $2 \mu \mathrm{m}$. ctrl = healthy control, $\mathrm{pt}=$ patient. 
the lack of response to arachidonic acid. In this case, inherited alterations of $\mathrm{TXA}_{2}$ synthesis pathway (e.g., hitting thromboxane synthase or cyclooxygenase) can be distinguished from defects of $\mathrm{TXA}_{2}$ receptor by assessing the aggregation in response to a $\mathrm{TXA}_{2}$ analog. ${ }^{62}$

More frequently, LTA shows patterns shared by more IPDs. The absence of the secondary aggregation wave in response to ADP and/or epinephrine, for example, is commonly observed in IPDs featured by dense granule disturbance or signaling defects. ${ }^{55,63}$ To refer to the methods discussed earlier, in such a case the assessment of dense granule structures by immunofluorescence is a straightforward option to narrow down the diagnosis.

LTA has some disadvantages: it requires a relatively large volume of blood, which is problematic particularly for children, is time consuming, and requires skilled manual processing of the samples. In addition, it is not appropriate in cases with thrombocytopenia since platelet function can be underestimated when platelet count in PRP is lower than 100 to $150 \times 10^{9} / \mathrm{L}{ }^{64}$ Moreover, the method is not completely standardized. ${ }^{8,65}$

Whole-blood impedance aggregometry is another available technique, which might be a reliable alternative to LTA at least for the detection of profound alterations of platelet function. ${ }^{66,67} \mathrm{~A}$ major advantage is using whole blood, thereby omitting the centrifugation step. In IPDs with platelet macrocytosis, the large platelets typically sediment with the red cells and do not remain in the PRP supernatant.

\section{Evaluation of the Content and Secretion of Platelet Granules}

Alpha- and dense platelet granules, as well as lysosomes and vacuoles, can be reliably investigated and quantified with transmission electron microscopy, which represents the gold standard methodology for this purpose. ${ }^{68,69}$ The content and the morphology of platelet granules and lysosomes can also be estimated by immunofluorescenceconfocal microscopy. ${ }^{70}$ Moreover, $\alpha$-granule components such as platelet factor 4 and $\beta$-thromboglobulin can be quantified in platelet lysates by commercially available enzyme-linked immunosorbent assay-based tests. ${ }^{8}$ However, these techniques are not widespread used in the routine yet, as they require close cooperation between physicians, first-level diagnostic centers, and specialized research laboratories. ${ }^{63}$

On the other hand, a comprehensive estimation of granule distribution, albeit less sophisticated, can be provided by the aforementioned traditional immunofluorescence microscopy on the blood smears. ${ }^{46}$ By using monoclonal antibodies against specific granule components, patterns of granule reduction or misdistribution, which are typical or highly suggestive for some IPDs, can be detected. In the presence of macro-thrombocytopenia with "pale" platelets, a major reduction of $\alpha$-granules is typical for GPS. ${ }^{71}$ Incomplete $\alpha$-granule reduction can be found in two other genetic macro-thrombocytopenias: GATA1-RT and GFI1B-RT. ${ }^{37,45,72}$
A mild-to-moderate granule disturbance is also present in two forms of autosomal dominant IPD with normal platelet dimension that predispose to acquired hematological malignancies: ETV6-RT (dense granules) and ANKRD26-RT ( $\alpha$ granules). ${ }^{73-75}$ This finding can guide the direction of further testing. In the absence of thrombocytopenia, granule reduction orientates toward $\alpha-, \delta$-, or combined storage pool diseases. ${ }^{5}$ Immunofluorescence can also identify abnormalities of granule dimensions, which could hint certain forms of IPD. In fact, enlarged $\alpha$-granules have been reported in the syndromic TCPT/Jacobsen syndrome. ${ }^{29}$ Moreover, heterogeneity in $\alpha$-granule diameter has been described in patients with inherited thrombocytopenia due to mutations in filamin A gene. ${ }^{49}$

Alpha granule release can be estimated by evaluating the surface expression of P-selectin (CD62P)-in resting conditions and upon platelet stimulation-by flow cytometry (FC), which represents the most commonly used method for this purpose. However, high CD62P expression can be found in patients affected by $\alpha$-granule disorders such as GPS, ${ }^{76}$ as CD62P, which cannot be integrated into the lacking granule membrane, is expressed on the cell surface. Therefore, results obtained after platelet activation should always be compared with the baseline level.

Although the gold standard for the assessment of dense granule secretion remains the measurement of the secretion of ${ }^{14} \mathrm{C}-5$-HT (serotonin) from platelets, ${ }^{77}$ the assessment of ATP release by lumiaggregometry is a well-established method that integrates the results of LTA. A primary secretion defect can then be confirmed by the measurement of ATP: ADP ratio in the platelet lysate, which is typically normal in this case and increased in granule deficiency. ${ }^{8}$ The dense granule release can also be measured by FC using the indirect marker of mepacrine uptake and release, ${ }^{78}$ thus avoiding the use of radioisotopes. ${ }^{79}$ The mepacrine test showed high sensitivity but low specificity for the identification of $\delta$ Storage Pool Deficiency (SPD) and has been proposed as a screening tool to exclude this condition. ${ }^{80}$ A systematic comparison of the effectiveness of these methods in clinical use would be desirable.

\section{Flow Cytometry}

The assessment of surface expression of platelet antigens and activation markers play an important role in the first-line IPD diagnostic workup. Although suffering from poor standardization, the method is long established and requires small amounts of blood, which, however, has to be analyzed within 24 hours after bloodletting in case of activation markers (membrane glycoproteins are stable for 1-2 days at least to identify severe deficiency). ${ }^{62,81,82}$ Partial-to-complete decrease of certain surface glycoproteins typically characterizes some IPDs. In biallelic BSS and classical GT, the expression of GpIb/IX and GpIIb/IIIa, respectively, is strongly reduced or even absent. The same glycoproteins are partially reduced in monoallelic BSS and in dominant GT. ${ }^{83,84}$ If the suspicion of these two disorders is raised by the immunofluorescence analysis on the blood smear, the role of FC for 
confirmation is particularly important when the reduction is partial, as immunofluorescence is at best semiquantitative. ${ }^{46}$ Similarly, deficiencies of GpVI and Gpla/IIa can be found by FC. ${ }^{85,86}$

The FC measurement of activation parameters such as CD62P or the activated form of GpIIb/IIIa (recognized by the antibody PAC1) can integrate the results of LTA in response to specific agonists, or may even substitute for classical aggregation studies in children. In GT, the binding of PAC1 is typically absent. The same alteration has also been described in two IPDs with normal platelet count and impaired platelet function: the Stormorken syndrome and the platelet defect of protein kinase $\mathrm{C}^{8}$ Using the fluorescent dye mepacrine, which is internalized into platelet granules, dense granule secretion can also be assessed by FC. ${ }^{80}$

By exposing anionic phospholipids on the membrane, activated platelets provide a stimulating surface for the coagulation cascade, thus promoting thrombin generation. ${ }^{87} \mathrm{FC}$ assessment of phosphatidylserine expression by annexin $\mathrm{V}$ binding can be of aid in diagnosing IPDs with enhanced or impaired procoagulant activity of platelets as reported in Stormorken and Scott syndrome, respectively. ${ }^{87-89}$

Methodologies combining FC with microscopy (i.e., imaging FC), fluorescence labeling (i.e., multiplexed FC), or microfluidic techniques (i.e., real-time deformation cytometry, RT-DC) represent new generation tests, which seem promising for studying IPDs with high throughput and novel approaches, ${ }^{90-93}$ but they are not well established for patient diagnosis, yet.

\section{Other Tests}

Clot retraction evaluates the interaction of platelet GpIIb/IIIa with fibrin in the forming clot. ${ }^{94}$ This method is wellestablished for diagnosing GT. ${ }^{95}$ In the field of IPDs, alterations of clot retraction have also been described in WAS and Stormorken syndrome. However, its sensitivity for minor alterations of platelet function is low. ${ }^{56}$

Platelet activity can also be studied by measuring soluble markers. For instance, the assessment of the $\mathrm{TXB}_{2}$ in serum, in urine, or in the supernatant of PRP can indicate IPDs with impaired metabolism of arachidonic acid (e.g., inherited defects of thromboxane or cyclooxygenase synthase, or cytosolic phospholipase $A_{2}$ ). Nevertheless, this test is timeconsuming and available only in specialized laboratories. ${ }^{8,96}$ By using multicolor fluorescence beads, FC allows simultaneous quantitative evaluation of circulating parameters, ${ }^{97}$ for instance the in vivo platelet activation marker plasmatic soluble P-selectin. ${ }^{98}$ Although this modality is more frequently used in research than in the diagnostic workup of patients, it might be of aid in the IPD field when the available blood sample is limited, for instance in pediatric patients.

\section{Genetic Testing}

Sanger sequencing has been used for a long time for the molecular confirmation of a small group of IPDs with welldefined genetic causes. Over the past 15 years, with the coming of the high-throughput sequencing (HTS), the genet- ic analysis has achieved a prominent role even among the first-line diagnostic tools for IPDs. ${ }^{99,100}$

Targeted HTS allows for the simultaneous analysis of more genes with ever-shorter turnaround time and cheaper costs. Accordingly, specific diagnostic panels have been created for IPDs, or subgroups of IPDs (e.g., macro-thrombocytopenias) whose phenotype can be caused by several genes. ${ }^{101}$ Various groups have tested this approach in the field of IPDs, and the global diagnostic rate appeared to be around 50\% for inherited thrombocytopenias and around $25 \%$ for inherited alterations of platelet function, respectively. ${ }^{102-115}$ On the other hand, targeted sequencing usually unravels many variants of uncertain significant (VUS), whose correlation with the phenotype can be complicated, especially when the clinical presentation is blurred or the referring clinicians are not adequately skilled in genetic interpretation. Guidelines based on multidisciplinary expertise (i.e., geneticists, clinicians, bioinformaticians) have been created to classify variants as pathogenic, likely pathogenic or benign, thus reducing the number of unresolved cases. ${ }^{116-118}$ Moreover, the creation of shared databases for VUS-once the sensitive data of the patients have been de-identified-has been proposed to improve the understanding of the possible pathogenic significance of such variants. ${ }^{119-121}$ Here, the functional analyses and the immune-morphologic assessment on the blood smear are highly complementary to genetic testing. In fact, the presence of peculiar functional defects can provide evidence that the variant is causal as the patient displays the specific functional phenotype associated with that disease. Similarly, when typical changes of platelet markers are identified by immunofluorescence, the variant under examination is most likely pathogenic. Such pieces of evidence would be enough to upgrade a VUS to a likely pathogenic variant. However, in case of an unaltered platelet phenotype, the VUS is most likely not relevant.

A technical limitation of targeted sequencing is the inability to identify variants located in noncoding regions such as 3'UTR or promotor sites (if not targeted), which can be relevant for some IPDs. ${ }^{100}$ In addition, novel genes potentially responsible for IPDs are excluded from the analysis. These drawbacks can be overcome by extending the investigation to the entire exome or even genome with whole-exome sequencing (WES) and whole-genome sequencing (WGS). Here, the interpretation of the great amount of data is burdensome and often more expensive than the sequencing itself. Moreover, the sum of information, in particular related to new genes, deserves further studies to be interpreted. ${ }^{99}$ Lastly, despite calling algorithms are now available for research and clinical diagnostics, some structural variants that can be disease-causing -for example, complex copy number variations-can be difficult to detect even with HTS methods, including WGS. ${ }^{100,113,122,123}$

\section{Consequences of IPD Diagnosis}

Diagnosing IPDs has many positive impacts on the patients. First, it gives a reason for the laboratory alterations and 
possible hemorrhagic symptoms, which are usually chronic and therefore highly influencing their quality of life, even if mild. If the bleeding symptoms do not affect quality of life, often the repetitive control of the platelet count, restriction of sport activities in children, or mistreatment due to the wrong diagnosis of ITP by the treating physician does.

The bleeding treatment in IPDs is mostly symptomatic and includes general behavioral norms, antifibrinolytics, desmopressin, platelet transfusions, and recombinant factor VIIa (rFVIIa). ${ }^{124}$ Despite this, recognizing the specific IPD sometimes allows clinicians to suggest medications that are more likely to be effective. For instance, (nonsevere) mucosal bleedings in patients with inherited thrombocytopenias respond well to tranexamic acid. Conversely, desmopressin is a good option for covering hemostatic challenges in some patients with $\delta$ SPD. 2,125,126 Despite a similar presentation, type $2 \mathrm{~B}$ - and PT vWD are distinct diseases that deserve different treatments in case of bleeding, and a definite diagnosis is advisable. While platelet transfusions are effective in PT vWD, they should be avoided in type $2 \mathrm{~B} v W \mathrm{D}$, opting instead for von Willebrand factor supply. ${ }^{60,127}$

When platelet transfusions are indicated, the use of inline leukocyte-depleted platelet concentrates is recommendable in all patients with IPDs, especially when the bleeding phenotype is substantial and the probability to receive further transfusions is high. ${ }^{128}$ In GT, the risk of isoimmunization against the glycoprotein lacking on the patient's own platelets is one of the biggest risks for the patient, and platelet transfusions should be limited to situations in which other treatments are ineffective. rFVIIa is instead a better choice. $^{129}$

A definition of the specific IPD may be decisive also for the prognosis. Relevant genotype-phenotype correlations have been reported for some disorders, and the type of mutation can predict the severity of bleeding (as for null variants in GT) or the risk to develop throughout life nephropathy and hearing loss in MYH9-RD. ${ }^{2,18}$ Since therapeutic options to cure deafness and slow down the progression toward renal failure are available (i.e., cochlear implantation and reninangiotensin pathway inhibitors, respectively), the genotype definition informs the therapeutic choices and the surveillance schedule. ${ }^{130,131}$

Thrombopoietin-mimetic drugs such as eltrombopag and romiplostim have recently entered the field of treatment of IPDs, as some forms proved to respond to these drugs, which represent a promising alternative to platelet transfusions especially for elective surgery. ${ }^{132-136}$ The genetic confirmation, in this case, is important to offer the patients such option.

Patients affected with ANKRD26-RT, ETV6-RT, and thrombocytopenia due to mutations in RUNX1 are at higher risk to develop hematological malignancies. ${ }^{137}$ The molecular definition, albeit not yet helpful to predict the individual risk, can be relevant in the view of an early search for a stem cell donor in the family for transplantation. In this case, it is crucial to exclude as candidate donors all family members, who carry the same IPDcausing genetic variant as the recipient. ${ }^{13}$ Nonetheless, recognizing one of these forms has also a problematic side. As the possibilities to estimate the individual risk for leukemia is poor, and no treatment for prevention of development of leukemia exists yet, the diagnosis may cause psychological distress to the patient in the absence of major benefits. Patients who have been diagnosed with one of these forms can find comfort in the planning of a follow-up program. However, the type and the timing of the examinations to be performed are difficult to establish. Some guidance is given in reviews authored by University of Chicago Hematopoietic Malignancies Cancer Risk Team $^{138}$ and by Pecci \& Balduini. ${ }^{139}$

Prenatal diagnosis and preimplantation testing for IPDs are possible, and are generally regarded as a personal decision of the family. ${ }^{140}$ However, a careful counseling from the medical professionals is advisable, particularly in case of disorders with possible acquired hematological or extrahematological manifestations impacting the morbidity and the quality of life of the patients. ${ }^{9}$ The medical history of the affected family members, the possible presence of genotypephenotype correlations to predict the evolution of the disease, and the availability of therapeutic or preventive measures can orient the final decision on the use of prenatal testing in the case at hand. ${ }^{18,130,131}$

Genetic testing performed for IPDs can also detect incidental findings such as a carrier status for an unsuspected recessive disease (e.g., hemophilia $A$ ). This can influence the reproductive choices of the patients, and eventually generate apprehension. Therefore, the possible desire "not-toknow" of the patient should be safeguarded when planning genetic investigations. ${ }^{141,142}$ A group of experts joining the Subcommittee on Genomics in Thrombosis and Hemostasis of International Society on Thrombosis and Haemostasis (ISTH) recently approached this delicate issue. Briefly, they agreed to recommend the use of targeted multigene panels for diagnosing IPDs, as long as the candidate genes are selected based on an accurate phenotype evaluation. ${ }^{13}$ In addition, a guideline for the acquisition of the informed consent with active involvement of patients (or parents, in case of probands of minor age) has been proposed (-Table 2).

In summary, phenotyping of patients suspected to have an IPD consists of several aspects: (1) clinical phenotyping; (2) platelet phenotyping, including platelet function (by different laboratory techniques) and platelet morphology (by light microscopy and immunofluorescence microscopy); and (3) genetic phenotyping. In combination, this allows to diagnose the underlying IPD in approximately 50 to $60 \%$ of patients with IPDs associated with thrombocytopenia and in 20 to $30 \%$ of patients with an IPD with normal platelet counts but platelet function defects. Despite the major progress in the understanding of IPDs achieved during the last decade, still a lot has to be done to improve diagnosis and management of IPDs. The clotting cascade consists of less than 50 different proteins, while in platelets more than 2,000 different proteins have been identified. 
Table 2 Guidance for discussion and recommended text to be included in an informed consent for genetic testing of IPD proposed by the Subcommittee on Genomics in Thrombosis and Hemostasis of the International Society on Thrombosis and Haemostasis (ISTH)

\section{Recommended items to include in the informed consent of diagnostic panel-based HTS for IPDs}

\section{Information:}

What is an HTS test for IPDs?

Information:

What are the limitations of an HTS test?

Information:

What type of genetic report will I receive?

\section{Information:}

Implication for family members

Information:

Are there any risks involved?

Patient choice:

Opt-in/Opt-out choice for testing of IPD genes that are also associated with an increased risk of leukemia
Example of text for informed consent for patients (in between brackets is adjusted informed consent for parents)

You (or your child) are/is suspected of having an IPD based on clinical and/or laboratory evidence and/or family history. This might include platelet dysfunction or an abnormal low platelet count (thrombocytopenia) associated with bleeding or other clinical symptoms. These symptoms may be caused by a change in the DNA of a specific gene, called a variant, that may have been passed down from generation to generation or occurs for the first time as a novel variant (de novo). A confirmative genetic diagnosis of this IPD can sometimes be obtained using an HTS test. The test is a DNA-based analysis of all genes that are currently known to cause an IPD

Some IPDs cannot be explained by a genetic diagnosis because the gene defects for these disorders are not yet known or the genetic change may be missed because of technical limitations of the test. Sometimes a genetic change is found, but it is not clear whether it is the cause of an IPD or not. These are known as "variants of uncertain significance" (VUS).

You (or your child) can receive three types of genetic reports when HTS test is performed: (1) a disease-causing, referred to as pathogenic, DNA variant is found that can explain your IPD (the IPD in your child); (2) no DNA variant is found that can explain your IPD (the IPD in your child); and (3) a DNA variant is found that requires further studies because its clinical significance is not clear. This type of variant is sometimes referred to as a VUS

The results of a genetic test for IPD are likely to have implications for your (your child's) family members. It is encouraged to discuss that you (your child) are being tested for an IPD with your (your child's) family. Your (your child's) family members can be informed about the option for genetic counseling. You may be asked to share your (your child's) genetic test report with the clinician of family members

A genetic change may be identified that indicates a disorder, or the risk of having or carrying a disorder, that is not part of the IPD that you (your child) are being tested for.

There may be unexpected findings. For example, the results might indicate that the relationship between family members is not what is expected

The HTS test includes three genes (RUNX1, ETV6, and ANKRD26) that if a pathogenic variant is discovered, is associated with an increased risk of leukemia (blood cancer), in addition to causing my IPD (the IPD in my child). The estimated risk for leukemia differs between these three genes. Close to one-half of patients ( 44\%) with a variant in RUNX1 develop a blood cancer. The average age of onset is 33 years and $\sim 25 \%$ who are diagnosed with a blood cancer are children. About one in three patients with ETV6 variants develops leukemia. Among those who develop leukemia, most are children. About 1 in 20 patients with an ANKRD26 variant develops leukemia. Among those who develop leukemia, most are adults.

Knowing the genetic variant will not help my clinician (the clinician of my child) predict my (his/her) precise risk for developing leukemia, but the clinician can regularly test my (his/her) blood cell count and look for changes in my (his/her) bone marrow more closely. It is possible that close surveillance could help detect a blood cancer early and knowing the genetic variant would impact donor selection for bone marrow transplant.

I understand that a genetic test cannot prevent leukemia.

I understand that I have the "right not to know" about these incidental findings. I have chosen (for my child) to analyze these three genes: (YES) or (NO).

Patient choice:

Participation to the HTS test is voluntary I understand that my participation (the participation of my child) to the HTS test for IPD is voluntary and that I am free to withdraw this participation (the participation of my child) at any time, without giving any reason and this will not alter the clinical care I (my child) receive. In this case, any further addition of data to my record (the record of my child) will be stopped

Patient choice:

Sharing variants with other health care specialists to improve disease knowledge

My anonymized genetic variants (or genetic variants of my child) can be shared among health care professionals and laboratory scientists nationally or internationally in publicly accessible databases. This is done to compare the findings from patients with similar symptoms or variants, which can help determine which variants may or may not be linked to a particular condition. Sharing data can also support ongoing research aimed at understanding how genetic variants cause disease and may potentially support the discovery of new treatments for a specific inherited condition. My privacy and my health status (the privacy and the health status of my child) is fully respected upon sharing the genetic information. No personal data are shared among other health care professionals or scientists. All data will be anonymized 
Table 2 (Continued)

\begin{tabular}{|l|l|}
\hline $\begin{array}{l}\text { Recommended items to } \\
\text { include in the informed } \\
\text { consent of diagnostic } \\
\text { panel-based HTS for IPDs }\end{array}$ & $\begin{array}{l}\text { Example of text for informed consent for patients (in between brackets is adjusted } \\
\text { informed consent for parents) }\end{array}$ \\
\hline $\begin{array}{l}\text { Patient choice: } \\
\text { Acknowledgment of } \\
\text { expectations related to an } \\
\text { HTS test for IPD }\end{array}$ & $\begin{array}{l}\text { I want to know the genetic cause of my IPD (of the IPD present in my child). I have been told } \\
\text { and understand how information about the genetic cause of my IPD may or may not change } \\
\text { my clinical care (the clinical care of my child). I have been informed about the option for } \\
\text { genetic counseling }\end{array}$ \\
\hline Additional items that can be included \\
\hline $\begin{array}{l}\text { Patient choice: } \\
\begin{array}{l}\text { Opt-in/Opt-out choice for } \\
\text { further studies of a VUS }\end{array}\end{array} \quad \begin{array}{l}\text { If my report (the report of my child) contains a DNA variant(s) that requires further studies and } \\
\text { from which the relevance for my (their) IPD is not clear, I grant permission for my clinician to } \\
\text { recontact me (on behalf of my child) for further studies: (YES) or (NO) }\end{array}$ \\
\hline $\begin{array}{l}\text { Patient choice: } \\
\begin{array}{l}\text { Opt-in/Opt-out choice for } \\
\text { information regarding } \\
\text { carriership of recessive } \\
\text { conditions and implications }\end{array}\end{array} \quad \begin{array}{l}\text { I would like to receive details of DNA variants that I carry (that my child carries). These DNA } \\
\text { variants are not always directly related to my clinical condition (the clinical condition of my } \\
\text { child). I want to know if I (my child) carry (carries) a DNA variant for a recessive disease: } \\
\text { (YES) or (NO) }\end{array}$ \\
\hline
\end{tabular}

Abbreviations: HTS, High Throughput Sequencing; IPDs, Inherited Platelet Disorders; ISTH, International Society on Thrombosis and Haemostasis; VUS, Variants of Uncertain Significant.

Source: Modified from Downes et al. ${ }^{13}$

\section{Authors' Contributions}

C.Z., M.W., and A.G. wrote the article. All the authors approved the final version of the manuscript.

Conflict of Interests

The authors report no conflict of interest.

\section{Acknowledgment}

This work was supported by the Deutsche Forschungsgemeinschaft (DFG, German Research Foundation)-project number: 374031971-TRR 240.

\section{References}

1 Nurden AT, Nurden P. Inherited thrombocytopenias: history, advances and perspectives. Haematologica 2020;105(08):2004-2019

2 Nurden P, Stritt S, Favier R, Nurden AT. Inherited platelet diseases with normal platelet count: phenotypes, genotypes and diagnostic strategy. Haematologica 2021;106(02):337-350

3 Megy K, Downes K, Simeoni I, et al; Subcommittee on Genomics in Thrombosis and Hemostasis. Curated disease-causing genes for bleeding, thrombotic, and platelet disorders: communication from the SSC of the ISTH. J Thromb Haemost 2019;17(08): 1253-1260

4 Balduini CL, Pecci A, Noris P. Inherited thrombocytopenias: the evolving spectrum. Hamostaseologie 2012;32(04):259-270

5 Gresele P, Bury L, Falcinelli E. Inherited platelet function disorders: algorithms for phenotypic and genetic investigation. Semin Thromb Hemost 2016;42(03):292-305

6 Pecci A, Balduini CL. Lessons in platelet production from inherited thrombocytopenias. Br J Haematol 2014;165(02):179-192

7 Noris P, Pecci A. Hereditary thrombocytopenias: a growing list of disorders. Hematology (Am Soc Hematol Educ Program) 2017; 2017(01):385-399

8 Gresele P, Bury L, Mezzasoma AM, Falcinelli E. Platelet function assays in diagnosis: an update. Expert Rev Hematol 2019;12(01): 29-46
9 Melazzini F, Zaninetti C, Balduini CL. Bleeding is not the main clinical issue in many patients with inherited thrombocytopaenias. Haemophilia 2017;23(05):673-681

10 Al-Huniti A, Kahr WH. Inherited platelet disorders: diagnosis and management. Transfus Med Rev 2020;34(04):277-285

11 Noris P, Schlegel N, Klersy C, et al; European Hematology Association - Scientific Working Group on Thrombocytopenias and Platelet Function Disorders. Analysis of 339 pregnancies in 181 women with 13 different forms of inherited thrombocytopenia. Haematologica 2014;99(08):1387-1394

12 Zaninetti C, Santini V, Tiniakou M, Barozzi S, Savoia A, Pecci A. Inherited thrombocytopenia caused by ANKRD26 mutations misdiagnosed and treated as myelodysplastic syndrome: report on two cases. J Thromb Haemost 2017;15(12):2388-2392

13 Downes K, Borry P, Ericson K, et al; Subcommittee on Genomics in Thrombosis, Hemostasis. Clinical management, ethics and informed consent related to multi-gene panel-based high throughput sequencing testing for platelet disorders: communication from the SSC of the ISTH. J Thromb Haemost 2020;18(10): 2751-2758

14 Althaus K, Najm J, Greinacher A. MYH9 related platelet disorders - often unknown and misdiagnosed. Klin Padiatr 2011;223(03): $120-125$

15 Stritt S, Nurden P, Turro E, et al; BRIDGE-BPD Consortium. A gainof-function variant in DIAPH1 causes dominant macrothrombocytopenia and hearing loss. Blood 2016;127(23):2903-2914

16 Albert MH, Bittner TC, Nonoyama S, et al. X-linked thrombocytopenia (XLT) due to WAS mutations: clinical characteristics, long-term outcome, and treatment options. Blood 2010;115 (16):3231-3238

17 Candotti F. Clinical manifestations and pathophysiological mechanisms of the Wiskott-Aldrich syndrome. J Clin Immunol 2018;38(01):13-27

18 Pecci A, Klersy C, Gresele P, et al. MYH9-related disease: a novel prognostic model to predict the clinical evolution of the disease based on genotype-phenotype correlations. Hum Mutat 2014;35 (02):236-247

19 Gresele P, Orsini S, Noris P, et al; BAT-VAL Study Investigators. Validation of the ISTH/SSC bleeding assessment tool for 
inherited platelet disorders: a communication from the Platelet Physiology SSC. J Thromb Haemost 2020;18(03):732-739

20 Orsini S, Noris P, Bury L, et al; European Hematology Association - Scientific Working Group (EHA-SWG) on thrombocytopenias and platelet function disorders. Bleeding risk of surgery and its prevention in patients with inherited platelet disorders. Haematologica 2017;102(07):1192-1203

21 Flaujac C, Boukour S, Cramer-Bordé E Platelets and viruses: an ambivalent relationship. Cell Mol Life Sci 2010;67(04):545-556

22 Miller AB, Hoogstraten B, Staquet M, Winkler A. Reporting results of cancer treatment. Cancer 1981;47(01):207-214

23 Rodeghiero F, Tosetto A, Abshire T, et al; ISTH/SSC Joint VWF and Perinatal/Pediatric Hemostasis Subcommittees Working Group. ISTH/SSC bleeding assessment tool: a standardized questionnaire and a proposal for a new bleeding score for inherited bleeding disorders. J Thromb Haemost 2010;8(09):2063-2065

24 Rodeghiero F, Pabinger I, Ragni M, et al. Fundamentals for a systematic approach to mild and moderate inherited bleeding disorders: an EHA Consensus Report. HemaSphere 2019;3(04): e286

25 Rydz N, James PD. The evolution and value of bleeding assessment tools. J Thromb Haemost 2012;10(11):2223-2229

26 Gresele P, Falcinelli E, Bury L, et al; BAT-VAL Study Investigators. The ISTH bleeding assessment tool as predictor of bleeding events in inherited platelet disorders: Communication from the ISTH SSC Subcommittee on Platelet Physiology. J Thromb Haemost 2021;19(05):1364-1371

27 Toriello HV. Thrombocytopenia-absent radius syndrome. Semin Thromb Hemost 2011;37(06):707-712

28 Niihori T, Ouchi-Uchiyama M, Sasahara Y, et al. Mutations in MECOM, encoding oncoprotein EVI1, cause radioulnar synostosis with amegakaryocytic thrombocytopenia. Am J Hum Genet 2015;97(06):848-854

29 Favier R, Akshoomoff N, Mattson S, Grossfeld P. Jacobsen syndrome: advances in our knowledge of phenotype and genotype. Am J Med Genet C Semin Med Genet 2015;169(03):239-250

30 Turro E, Greene D, Wijgaerts A, et al; BRIDGE-BPD Consortium. A dominant gain-of-function mutation in universal tyrosine kinase SRC causes thrombocytopenia, myelofibrosis, bleeding, and bone pathologies. Sci Transl Med 2016;8(328):328ra30

31 Reynolds TM. Sitosterolaemia: a rare cause of accelerated atherosclerosis. J Clin Pathol 2018;71(10):863

32 Nesin V, Wiley G, Kousi M, et al. Activating mutations in STIM1 and ORAI1 cause overlapping syndromes of tubular myopathy and congenital miosis. Proc Natl Acad Sci U S A 2014;111(11): 4197-4202

33 Markello T, Chen D, Kwan JY, et al. York platelet syndrome is a CRAC channelopathy due to gain-of-function mutations in STIM1. Mol Genet Metab 2015;114(03):474-482

34 Noris P, Klersy C, Gresele P, et al; Italian Gruppo di Studio delle Piastrine. Platelet size for distinguishing between inherited thrombocytopenias and immune thrombocytopenia: a multicentric, real life study. Br J Haematol 2013;162(01):112-119

35 Noris P, Biino G, Pecci A, et al. Platelet diameters in inherited thrombocytopenias: analysis of 376 patients with all known disorders. Blood 2014;124(06):e4-e10

36 Bottega R, Pecci A, De Candia E, et al. Correlation between platelet phenotype and NBEAL2 genotype in patients with congenital thrombocytopenia and $\alpha$-granule deficiency. Haematologica 2013;98(06):868-874

37 Monteferrario D, Bolar NA, Marneth AE, et al. A dominantnegative GFI1B mutation in the gray platelet syndrome. $\mathrm{N}$ Engl J Med 2014;370(03):245-253

38 Millikan PD, Balamohan SM, Raskind WH, Kacena MA. Inherited thrombocytopenia due to GATA-1 mutations. Semin Thromb Hemost 2011;37(06):682-689

39 Hatta K, Kunishima S, Suganuma H, Tanaka N, Ohkawa N, Shimizu T. A family having type $2 \mathrm{~B}$ von Willebrand disease with a novel VWF p.R1308S mutation: detection of characteristic platelet aggregates on peripheral blood smears as the key aspect of diagnosis. Thromb Res 2015;136(04):813-817

40 Federici AB, Mannucci PM, Castaman G, et al. Clinical and molecular predictors of thrombocytopenia and risk of bleeding in patients with von Willebrand disease type $2 \mathrm{~B}$ : a cohort study of 67 patients. Blood 2009;113(03):526-534

41 Othman M, Lopez JA, Ware J. Platelet-type von Willebrand disease update: the disease, the molecule and the animal model. Expert Rev Hematol 2011;4(05):475-477

42 Savoia A, De Rocco D, Panza E, et al. Heavy chain myosin 9-related disease (MYH9 -RD): neutrophil inclusions of myosin-9 as a pathognomonic sign of the disorder. Thromb Haemost 2010;103 (04):826-832

43 Balduini CL, Pecci A, Loffredo G, et al. Effects of the R216Q mutation of GATA-1 on erythropoiesis and megakaryocytopoiesis. Thromb Haemost 2004;91(01):129-140

44 Neff AT. Sitosterolemia's stomatocytosis and macrothrombocytopenia. Blood 2012;120(22):4283

45 Greinacher A, Pecci A, Kunishima S, et al. Diagnosis of inherited platelet disorders on a blood smear: a tool to facilitate worldwide diagnosis of platelet disorders. J Thromb Haemost 2017;15(07): 1511-1521

46 Zaninetti C, Greinacher A. Diagnosis of inherited platelet disorders on a blood smear. J Clin Med 2020;9(02):539

47 Bury L, Falcinelli E, Chiasserini D, Springer TA, Italiano JE Jr, Gresele P. Cytoskeletal perturbation leads to platelet dysfunction and thrombocytopenia in variant forms of Glanzmann thrombasthenia. Haematologica 2016;101(01):46-56

48 Savoia A, Kunishima S, De Rocco D, et al. Spectrum of the mutations in Bernard-Soulier syndrome. Hum Mutat 2014;35 (09):1033-1045

49 Nurden P, Debili N, Coupry I, et al. Thrombocytopenia resulting from mutations in filamin A can be expressed as an isolated syndrome. Blood 2011;118(22):5928-5937

50 Kunishima S, Nishimura S, Suzuki H, Imaizumi M, Saito H. TUBB1 mutation disrupting microtubule assembly impairs proplatelet formation and results in congenital macrothrombocytopenia. Eur J Haematol 2014;92(04):276-282

51 Kitamura K, Okuno Y, Yoshida K, et al. Functional characterization of a novel GFI1B mutation causing congenital macrothrombocytopenia. J Thromb Haemost 2016;14(07):1462-1469

52 Leinoe E, Kjaersgaard M, Zetterberg E, Ostrowski S, Greinacher A, Rossing M. Highly impaired platelet ultrastructure in two families with novel IKZF5 variants. Platelets 2020;18:1-6

53 Amoruso M, Alberio L, Nagy M. EDTA-related degranulation mimicking Storage Pool Disease. Am J Hematol 2018;93(09): 1192-1193

54 Born GVR. Aggregation of blood platelets by adenosine diphosphate and its reversal. Nature 1962;194:927-929

55 Alessi M-C, Sié P, Payrastre B. Strengths and weaknesses of light transmission aggregometry in diagnosing hereditary platelet function disorders. J Clin Med 2020;9(03):763

56 Gresele P, Falcinelli E, Bury L. Inherited platelet function disorders. Diagnostic approach and management. Hamostaseologie 2016;36(04):265-278

57 Berndt MC, Andrews RK. Bernard-Soulier syndrome. Haematologica 2011;96(03):355-359

58 Ruggeri ZM, Bader R, de Marco L. Glanzmann thrombasthenia: deficient binding of von Willebrand factor to thrombin-stimulated platelets. Proc Natl Acad Sci U S A 1982;79(19):6038-6041

59 Frontroth JP, Favaloro EJ. Ristocetin-induced platelet aggregation (RIPA) and RIPA mixing studies. Methods Mol Biol 2017; 1646:473-494

60 Othman M. Platelet-type von Willebrand disease and type 2B von Willebrand disease: a story of nonidentical twins when two different genetic abnormalities evolve into similar phenotypes. Semin Thromb Hemost 2007;33(08):780-786 
61 Dumont B, Lasne D, Rothschild C, et al. Absence of collageninduced platelet activation caused by compound heterozygous GPVI mutations. Blood 2009;114(09):1900-1903

62 Gresele P. Diagnosis of inherited platelet function disorders: guidance from the SSC of the ISTH. J Thromb Haemost 2015;13 (02):314-322

63 Dupuis A, Bordet J-C, Eckly A, Gachet C. Platelet $\delta$-storage pool disease: an update. J Clin Med 2020;9(08):2508

64 Femia EA, Scavone M, Lecchi A, Cattaneo M. Effect of platelet count on platelet aggregation measured with impedance aggregometry (Multiplate ${ }^{\mathrm{TM}}$ analyzer) and with light transmission aggregometry. J Thromb Haemost 2013;11(12):2193-2196

65 Cattaneo M, Cerletti C, Harrison P, et al. Recommendations for the standardization of light transmission aggregometry: a consensus of the working party from the platelet physiology subcommittee of SSC/ISTH. J Thromb Haemost 2013;11(06): 1183-1189

66 Würtz M, Hvas AM, Christensen KH, Rubak P, Kristensen SD, Grove EL. Rapid evaluation of platelet function using the Multiplate ${ }^{\circledR}$ Analyzer. Platelets 2014;25(08):628-633

67 Al Ghaithi R, Drake S, Watson SP, Morgan NV, Harrison P. Comparison of multiple electrode aggregometry with lumiaggregometry for the diagnosis of patients with mild bleeding disorders. J Thromb Haemost 2017;15(10):2045-2052

68 Clauser S, Cramer-Bordé E Role of platelet electron microscopy in the diagnosis of platelet disorders. Semin Thromb Hemost 2009; 35(02):213-223

69 Cramer EM, Meyer D, le Menn R, Breton-Gorius J. Eccentric localization of von Willebrand factor in an internal structure of platelet alpha-granule resembling that of Weibel-Palade bodies. Blood 1985;66(03):710-713

70 Sehgal S, Storrie B. Evidence that differential packaging of the major platelet granule proteins von Willebrand factor and fibrinogen can support their differential release. J Thromb Haemost 2007;5(10):2009-2016

71 Gunay-Aygun M, Falik-Zaccai TC, Vilboux T, et al. NBEAL2 is mutated in gray platelet syndrome and is required for biogenesis of platelet $\alpha$-granules. Nat Genet 2011;43(08):732-734

72 Freson K, Wijgaerts A, Van Geet C. GATA1 gene variants associated with thrombocytopenia and anemia. Platelets 2017;28(07): 731-734

73 Noetzli L, Lo RW, Lee-Sherick AB, et al. Germline mutations in ETV6 are associated with thrombocytopenia, red cell macrocytosis and predisposition to lymphoblastic leukemia. Nat Genet. 2015;47(05):535-538

74 Melazzini F, Palombo F, Balduini A, et al. Clinical and pathogenic features of ETV6-related thrombocytopenia with predisposition to acute lymphoblastic leukemia. Haematologica. 2016;101(11): 1333-1342

75 Noris P, Perrotta S, Seri M, et al. Mutations in ANKRD26 are responsible for a frequent form of inherited thrombocytopenia: Analysis of 78 patients from 21 families. Blood. 2011;117(24): 6673-6680

76 Nurden AT, Nurden P. The gray platelet syndrome: clinical spectrum of the disease. Blood Rev 2007;21(01):21-36

77 Mumford AD, Frelinger AL III, Gachet C, et al. A review of platelet secretion assays for the diagnosis of inherited platelet secretion disorders. Thromb Haemost 2015;114(01):14-25

78 Skaer RJ, Flemans RJ, McQuilkan S. Mepacrine stains the dense bodies of human platelets and not platelet lysosomes. $\mathrm{Br} \mathrm{J}$ Haematol 1981;49(03):435-438

79 Rendu F, Nurden AT, Lebret M, Caen JP. Relationship between mepacrine-labelled dense body number, platelet capacity to accumulate 14C-5-HT and platelet density in the Bernard-Soulier and Hermansky-Pudlak syndromes. Thromb Haemost 1979;42 (02):694-704

80 van Asten I, Blaauwgeers M, Granneman L, et al. Flow cytometric mepacrine fluorescence can be used for the exclusion of platelet dense granule deficiency. J Thromb Haemost 2020;18(03): 706-713

81 Shattil SJ, Cunningham M, Hoxie JA. Detection of activated platelets in whole blood using activation-dependent monoclonal antibodies and flow cytometry. Blood 1987;70(01):307-315

82 van Asten I, Schutgens REG, Urbanus RT. Toward flow cytometry based platelet function diagnostics. Semin Thromb Hemost 2018;44(03):197-205

83 Noris P, Perrotta S, Bottega R, et al. Clinical and laboratory features of 103 patients from 42 Italian families with inherited thrombocytopenia derived from the monoallelic Ala156Val mutation of GPIb $\alpha$ (Bolzano mutation). Haematologica 2012;97 (01):82-88

84 Bury L, Zetterberg E, Leinøe EB, et al. A novel variant Glanzmann thrombasthenia due to co-inheritance of a loss- and a gain-offunction mutation of ITGB3: evidence of a dominant effect of gain-of-function mutations. Haematologica 2018;103(06): e259-e263

85 Hermans C, Wittevrongel C, Thys C, Smethurst PA, Van Geet C, Freson K. A compound heterozygous mutation in glycoprotein VI in a patient with a bleeding disorder. J Thromb Haemost 2009;7 (08):1356-1363

86 Noris P, Guidetti GF, Conti V, et al. Autosomal dominant thrombocytopenias with reduced expression of glycoprotein Ia. Thromb Haemost 2006;95(03):483-489

87 Solum NO. Procoagulant expression in platelets and defects leading to clinical disorders. Arterioscler Thromb Vasc Biol 1999;19(12):2841-2846

88 van Geffen JP, Swieringa F, Heemskerk JWM. Platelets and coagulation in thrombus formation: aberrations in the Scott syndrome. Thromb Res 2016;141(Suppl 2):S12-S16

89 Halliez M, Fouassier M, Robillard N, et al. Detection of phosphatidyl serine on activated platelets' surface by flow cytometry in whole blood: a simpler test for the diagnosis of Scott syndrome. Br J Haematol 2015;171(02):290-292

90 Zhou Y, Yasumoto A, Lei C, et al. Intelligent classification of platelet aggregates by agonist type. eLife 2020;9:e52938

91 Spurgeon BEJ, Naseem KM. Phosphoflow cytometry and barcoding in blood platelets: Technical and analytical considerations. Cytometry B Clin Cytom 2020;98(02):123-130

92 Sachs L, Denker C, Greinacher A, Palankar R. Quantifying singleplatelet biomechanics: An outsider's guide to biophysical methods and recent advances. Res Pract Thromb Haemost 2020;4(03): 386-401

93 Zaninetti C, Sachs L, Palankar R. Role of platelet cytoskeleton in platelet biomechanics: current and emerging methodologies and their potential relevance for the investigation of inherited platelet disorders. Hamostaseologie 2020;40(03):337-347

94 Whyte CS, Mitchell JL, Mutch NJ. Platelet-mediated modulation of fibrinolysis. Semin Thromb Hemost 2017;43(02):115-128

95 Solh T, Botsford A, Solh M. Glanzmann's thrombasthenia: pathogenesis, diagnosis, and current and emerging treatment options. J Blood Med 2015;6:219-227

96 Patrono C, Rocca B. Measurement of thromboxane biosynthesis in health and disease. Front Pharmacol 2019;10:1244

97 Antal-Szalmás P, Nagy B Jr, Debreceni IB, Kappelmayer J. Measurement of soluble biomarkers by flow cytometry. EJIFCC 2013; 23(04):135-142

98 Falcinelli E, Francisci D, Belfiori B, et al. In vivo platelet activation and platelet hyperreactivity in abacavir-treated HIV-infected patients. Thromb Haemost 2013;110(02):349-357

99 Freson K, Turro E. High-throughput sequencing approaches for diagnosing hereditary bleeding and platelet disorders. J Thromb Haemost 2017;15(07):1262-1272

100 Ver Donck F, Downes K, Freson K. Strengths and limitations of high-throughput sequencing for the diagnosis of inherited bleeding and platelet disorders. J Thromb Haemost 2020;18 (08):1839-1845 
101 Bean LJH, Funke B, Carlston CM, et al; ACMG Laboratory Quality Assurance Committee. Diagnostic gene sequencing panels: from design to report-a technical standard of the American College of Medical Genetics and Genomics (ACMG). Genet Med 2020;22 (03):453-461

102 Lentaigne $C$, Freson $\mathrm{K}$, Laffan MA, Turro E, Ouwehand WHBRIDGE-BPD Consortium and the ThromboGenomics Consortium. Inherited platelet disorders: toward DNA-based diagnosis. Blood 2016;127(23):2814-2823

103 Simeoni I, Stephens JC, Hu F, et al. A high-throughput sequencing test for diagnosing inherited bleeding, thrombotic, and platelet disorders. Blood 2016;127(23):2791-2803

104 Leinøe E, Gabrielaite M, Østrup O, et al. Outcome of an enhanced diagnostic pipeline for patients suspected of inherited thrombocytopenia. Br J Haematol 2019;186(02):373-376

105 Downes K, Megy K, Duarte D, et al; NIHR BioResource. Diagnostic high-throughput sequencing of 2396 patients with bleeding, thrombotic, and platelet disorders. Blood 2019;134(23): 2082-2091

106 Andersson NG, Rossing M, Fager Ferrari M, et al. Genetic screening of children with suspected inherited bleeding disorders. Haemophilia 2020;26(02):314-324

107 Bury L, Megy K, Stephens JC, et al. Next-generation sequencing for the diagnosis of MYH9-RD: predicting pathogenic variants. Hum Mutat 2020;41(01):277-290

108 Bastida JM, Del Rey M, Lozano ML, et al. Design and application of a 23-gene panel by next-generation sequencing for inherited coagulation bleeding disorders. Haemophilia 2016;22(04): 590-597

109 Leinøe E, Zetterberg E, Kinalis S, et al. Application of wholeexome sequencing to direct the specific functional testing and diagnosis of rare inherited bleeding disorders in patients from the Öresund Region, Scandinavia. Br J Haematol 2017;179(02): 308-322

110 Maclachlan A, Watson SP, Morgan NV. Inherited platelet disorders: insight from platelet genomics using next-generation sequencing. Platelets 2017;28(01):14-19

111 Wang Q Cao L, Sheng G, et al. Application of high-throughput sequencing in the diagnosis of inherited thrombocytopenia. Clin Appl Thromb Hemost 2018;24(9, Suppl):94S-103S

112 Andres O, König E-M, Klopocki E, Schulze H. Use of targeted highthroughput sequencing for genetic classification of patients with bleeding diathesis and suspected platelet disorder. TH Open 2018 Dec 30; 2(04):e445-e454

113 Bastida JM, Lozano ML, Benito R, et al. Introducing high-throughput sequencing into mainstream genetic diagnosis practice in inherited platelet disorders. Haematologica 2018;103(01): 148-162

114 Heremans J, Freson K. High-throughput sequencing for diagnosing platelet disorders: lessons learned from exploring the causes of bleeding disorders. Int J Lab Hematol 2018;40 (Suppl 1):89-96

115 Johnson B, Doak R, Allsup D, et al; UK GAPP Study Group. A comprehensive targeted next-generation sequencing panel for genetic diagnosis of patients with suspected inherited thrombocytopenia. Res Pract Thromb Haemost 2018;2(04):640-652

116 Richards S, Aziz N, Bale S, et al; ACMG Laboratory Quality Assurance Committee. Standards and guidelines for the interpretation of sequence variants: a joint consensus recommendation of the American College of Medical Genetics and Genomics and the Association for Molecular Pathology. Genet Med 2015;17 (05):405-424

117 Matthijs G, Souche E, Alders M, et al; EuroGentest European Society of Human Genetics. Guidelines for diagnostic nextgeneration sequencing. Eur J Hum Genet 2016;24(01):2-5

118 Gomez K, Laffan M, Keeney S, Sutherland M, Curry N, Lunt P. Recommendations for the clinical interpretation of genetic variants and presentation of results to patients with inherited bleeding disorders. A UK Haemophilia Centre Doctors' Organisation Good Practice Paper. Haemophilia 2019;25(01): 116-126

119 Landrum MJ, Lee JM, Benson M, et al. ClinVar: public archive of interpretations of clinically relevant variants. Nucleic Acids Res 2016;44(D1):D862-D868

120 Vears DF, Sénécal K, Borry P. Reporting practices for variants of uncertain significance from next generation sequencing technologies. Eur J Med Genet 2017;60(10):553-558

121 McVey JH, Rallapalli PM, Kemball-Cook G, et al. The European Association for Haemophilia and Allied Disorders (EAHAD) coagulation factor variant databases: important resources for haemostasis clinicians and researchers. Haemophilia 2020;26 (02):306-313

122 Kosugi S, Momozawa Y, Liu X, Terao C, Kubo M, Kamatani Y. Comprehensive evaluation of structural variation detection algorithms for whole genome sequencing. Genome Biol 2019; 20(01): 117

123 Whitford W, Lehnert K, Snell RG, Jacobsen JC. Evaluation of the performance of copy number variant prediction tools for the detection of deletions from whole genome sequencing data. J Biomed Inform 2019;94:103174

124 Lambert MP. Inherited platelet disorders: a modern approach to evaluation and treatment. Hematol Oncol Clin North Am 2019; 33(03):471-487

125 Winikoff R, Scully MF, Robinson KS. Women and inherited bleeding disorders - a review with a focus on key challenges for 2019. Transfus Apheresis Sci 2019;58(05):613-622

126 Colucci G, Stutz M, Rochat S, et al. The effect of desmopressin on platelet function: a selective enhancement of procoagulant COAT platelets in patients with primary platelet function defects. Blood 2014;123(12):1905-1916

127 Othman M, Gresele P. Guidance on the diagnosis and management of platelet-type von Willebrand disease: a communication from the Platelet Physiology Subcommittee of the ISTH. JThromb Haemost 2020;18(08):1855-1858

128 Estcourt LJ, Birchall J, Allard S, et al; British Committee for Standards in Haematology. Guidelines for the use of platelet transfusions. Br J Haematol 2017;176(03):365-394

129 Chitlur M, Rajpurkar M, Recht M, et al. Recognition and management of platelet-refractory bleeding in patients with Glanzmann's thrombasthenia and other severe platelet function disorders. Int J Gen Med 2017;10:95-99

130 Pecci A, Granata A, Fiore CE, Balduini CL. Renin-angiotensin system blockade is effective in reducing proteinuria of patients with progressive nephropathy caused by MYH9 mutations (Fechtner-Epstein syndrome). Nephrol Dial Transplant 2008;23 (08):2690-2692

131 Pecci A, Verver EJ, Schlegel N, et al. Cochlear implantation is safe and effective in patients with MYH9-related disease. Orphanet J Rare Dis 2014;9(01):100

132 Gröpper S, Althaus K, Najm J, et al. A patient with Fechtner syndrome successfully treated with romiplostim. Thromb Haemost 2012;107(03):590-591

133 Zaninetti C, Barozzi S, Bozzi V, Gresele P, Balduini CL, Pecci A. Eltrombopag in preparation for surgery in patients with severe MYH9-related thrombocytopenia. Am J Hematol 2019;94(08): E199-E201

134 Zaninetti C, Gresele P, Bertomoro A, et al. Eltrombopag for the treatment of inherited thrombocytopenias: a phase II clinical trial. Haematologica 2020;105(03):820-828

135 Rodeghiero F, Pecci A, Balduini CL. Thrombopoietin receptor agonists in hereditary thrombocytopenias. J Thromb Haemost 2018;16(09):1700-1710

136 Westbury SK, Downes K, Burney C, et al. Phenotype description and response to thrombopoietin receptor agonist in DIAPH1-related disorder. Blood Adv. 2018;2(18): 2341-2346 
137 Galera P, Dulau-Florea A, Calvo KR. Inherited thrombocytopenia and platelet disorders with germline predisposition to myeloid neoplasia. Int J Lab Hematol 2019;41(Suppl 1): 131-141

138 University of Chicago Hematopoietic Malignancies Cancer Risk Team. How I diagnose and manage individuals at risk for inherited myeloid malignancies. Blood 2016;128(14): 1800-1813

139 Pecci A, Balduini CL. Inherited thrombocytopenias: an updated guide for clinicians. Blood Rev 2020;48:100784
140 Porter CC, Di Paola J, Pencheva B. ETV6 thrombocytopenia and predisposition to leukemia. In: Adam MP, Ardinger $\mathrm{HH}$, Pagon RA, et al, eds. GeneReviews ${ }^{\circledR}$ [Internet]. Seattle, WA: University of Washington; 1993-2021

141 Greinacher A, Eekels JJM. Simplifying the diagnosis of inherited platelet disorders? The new tools do not make it any easier. Blood 2019;133(23):2478-2483

142 Greinacher A, Eekels JJM. Diagnosis of hereditary platelet disorders in the era of next-generation sequencing: "primum non nocere". J Thromb Haemost 2019;17(03):551-554 